\title{
Peptide-protein interactions within human hair keratins
}

\author{
Célia F. Cruz, Nuno G. Azoia, Teresa Matamá, Artur Cavaco-Paulo* \\ CEB - Centre of Biological Engineering, University of Minho, 4710-057 Braga, Portugal
}

\section{A R T I C L E I N F O}

\section{Article history:}

Received 10 October 2016

Received in revised form 6 March 2017

Accepted 10 March 2017

Available online 16 March 2017

\section{Keywords:}

Peptide microarray

Hair keratin

Cosmetic peptide

Cysteine

Hydrophobicity

\begin{abstract}
A B S T R A C T
We selected 1235 decapeptides from human hair proteins encoded by human genes of keratins and keratin associated proteins. The peptides were linked to glass arrays and screened for their affinity towards a solution of human hair extracted keratin fraction. Based on the physicochemical properties of the peptides, ten variables were studied: content of different types of amino acid side chains (cysteine, hydrophobic, polar, basic, acidic, aromatic rings, amide, alcohol side chains), isoelectric point, and net charge. We found differences statistically significant on the binding affinity of peptides based on their content of cysteine, hydrophobic and polar amino acids, mainly containing alcohols. These results point to the formation of hydrophobic interactions and disulfide bonds between small peptides and human hair keratins as the main driving forces for the interaction of possible cosmetic peptides, namely designed to strength human hair. As so, our results enlighten the nature of the interaction of keratin based materials with human hair, which are claimed to enhance hair fiber strength, and enable a more directed and sustained hair care peptide design.
\end{abstract}

(C) 2017 Elsevier B.V. All rights reserved.

\section{Introduction}

Keratin is a fibrous structural protein, member of the superfamily of intermediate filament proteins, and one of the most important biopolymers in animals. Keratin has one of the high toughness among biomaterials [1]. This protein composes the hard integuments in mammals, such as hair, epidermis, wool, horns and also feathers, claws, and beaks of birds and reptiles. Traditionally, keratins can be classified, according to their tissue of origin and amount of sulfur. Soft keratins (e.g. from epidermis) have low sulfur content, and hard keratins (e.g. hair, nails, claws, beaks, quills) have a more coherent structure with a higher amount of sulfur [1,2]. Taking into account the classification of intermediate filament proteins (into six types based on sequence homology), keratins belong to the acidic Type I and neutral-basic Type II. Therefore, keratin protein family can be divided into type I a and type II a (acidic or neutralbasic "hard" keratins) and type I b and II b (acidic or neutral-basic "soft" keratins) [2]. The formation of a heterodimer by the parallel alignment of a single pair of type I and type II keratin polypeptides is the first step in the assembly of a keratin intermediate filament [3]. The heterodimers then aggregate into an antiparallel and shifted arrangement to form structural units of a higher order.

\footnotetext{
* Corresponding author.

E-mail address: artur@deb.uminho.pt (A. Cavaco-Paulo).
}

Approximately $80 \%$ of total mass of the hair fiber is composed by keratin [4]. The hair fiber is a stratified hard-cornified epithelium, continuously produced by the follicle (living part of the hair, buried deeply in the skin) [3]. The hair fiber consists of three concentric morphological constituents that act mechanically as a whole [5]. The cuticle, the outer protective layer of the hair, consists of plate-shaped cells that overlap longitudinally and peripherally. The cortex, the thickest part of the hair fiber, is composed of spindle-shaped cells containing macrofibrils and intermacrofibrillar material. The medulla, the innermost part of the coarser hairs that do not always exist, consists of hollow cells with a cytoskeleton of amorphous proteins and fine filaments [4,5]. The cell membrane complex works as a cement that glues overlapping cuticle cells, cuticle and cortex cells, and neighboring cortex cells together and is mainly composed of lipids and proteins [5]. Hair fiber is mostly constituted by hard keratins type I a and II a that aggregate into macrofibrils imbibed in a protein material called the matrix. The matrix is composed by the keratin associated proteins (KAPs). KAPs include high molecular weight sulfur proteins (50-75 kDa; $20 \%$ cysteine residues); ultra-high sulfur proteins (30-40\% cystine); and a lower molecular weight glycine-tyrosine rich proteins (15-50 kDa) $[6,7]$.

The mechanical properties of hair fibers depend on the interactions between its several morphological components, particularly, the interactions that stabilize the macromolecular structure of keratin fibers. These physicochemical interactions occur within and between keratin chains, between keratin and KAPs and within 
KAPs. They range from covalent bonds, such as disulfide and isopeptide bonds, to weaker interactions, such as hydrophobic interactions, hydrogen bonds, coulombic and van der Waals forces. The disulfide bridge is the major covalent bond, providing great chemical stability and the characteristic mechanical properties of hair. The weaker non-covalent polar bonds also represent an important interaction and, as they can be easily broken by water, they explain the dependence of the mechanical behavior of hair on humidity [5,8,9]. Bornschlögl and co-workers [10] have recently shown and proposed a sequence of events that explain the huge increase in the mechanical stiffening of keratin fibers during the keratinization and cornification process, which occurs above the follicle over the course of just $1 \mathrm{~mm}$. In an early stage, the mechanical stiffening is due to the increase in diameter of the keratin macrofibrils, their continuous compaction and parallel orientation, driven by the formation of isopeptide bonds, followed, in later stages, by the establishment of a disulfide network.

The desire for a healthy hair has created and sustains a huge industry of hair care products. To improve hair look and feel, several proteins, protein lysates, peptides and free amino acids are used in the composition of hair care products, mainly for hair strengthening and hair conditioning [11]. Low molecular weight peptides and amino acids can diffuse into hair cortex, assisting in the reduction of protein damage during repeated washing and chemical treatments and even improving physical and mechanical properties of hair fibers [12-16]. However, there is a limited knowledge and testing on how these peptides work, namely the nature of their interactions with hair and the best characteristics that these peptides should have leading to a higher affinity to hair keratins and performance according to their initial purpose.

In this study, we aim to understand better the properties of such peptides that can improve and reinforce the physical characteristics of the hair fiber. This work is motivated by the fact that typical and most common hair cosmetic procedures affect in greater or less extent the physicochemical and mechanical properties of hair, which often result in hair damage, and in more severe cases in scalp damage $[4,17,18]$. For this purpose, we designed an array of low molecular weight peptides from the entire proteome of human keratin and KAPs, to assess the ones with higher affinity and interaction with hair keratins and, consequently, with a putative ability to improve and reinforce the physical characteristics of the hair fiber. This is an innovative approach to the peptide design in hair care for two reasons: (1) it is based on a technique that allows a large screen and a global perspective on the most important forces during intermediate filament formation and stabilization (2) it is based on the human hair proteome. Several parameters were used to determine the peptide features that have statistical significance regarding their affinity to the hair. With a better understanding of the characteristics of the peptides with higher affinity to hair keratin, better cosmetic procedures can be created with inferior damage to the hair fiber and consumer's health.

\section{Experimental procedures}

\subsection{Materials}

Human hair was acquired from the International Hair Importers and Products, Inc. (New York, USA). Peptide microarray slides and the peptides were supplied from JPT Peptide Technologies GmbH (Berlin, Germany). All chemicals were purchased from SigmaAldrich (Portugal). Filtration systems were acquired from Merck Millipore (Germany) and Alexa Fluor ${ }^{\circledR} 647$ succinimidyl ester was obtained from Thermo Fischer Scientific (Portugal). Electrophoresis reagents were purchased from Bio-Rad (Portugal).

\subsection{Methods}

\subsubsection{Hair proteins extraction}

Keratin was extracted from human hair following a procedure adapted from Vasconcelos et al. [19] and Kazunori et al. [20]. Briefly, hair was immersed in a solution in a ratio $1: 10$ containing $8 \mathrm{M}$ urea as a chaotropic agent, $0.2 \mathrm{M}$ sodium dodecyl sulfate to stabilize the keratin solution and $0.5 \mathrm{M}$ sodium metabisulfite as reductant that allows keratin solubilization [20,21]. The mixture was heated to $50{ }^{\circ} \mathrm{C}$ for $24 \mathrm{~h}$ with constant agitation, for better desegregation of the hair fibers, and then filtered through a glass filter. The filtrate was dialyzed against distilled water using cellulose tubing molecular with a weight cut-off of $12-14 \mathrm{kDa}$. The mixture was further concentrated by ultrafiltration using an Amicon system with $3 \mathrm{kDa}$ nominal molecular weight limit.

\subsubsection{Characterization of hair keratin extracted: SDS-PAGE electrophoresis}

Sodium dodecyl sulfate-polyacrylamide (SDS-PAGE) gel electrophoresis was performed in accordance with the Bio-Rad manufacturer protocols, using a $12 \%$ of resolving gel and $4 \%$ of stacking gel, under denaturing conditions. A volume of $10 \mu \mathrm{L}$ of keratin extracted was electrophoresed on an SDS-PAGE gel at $20 \mathrm{~mA}$. Proteins were stained $\mathrm{d}$ using Coomassie blue staining and destained with a solution $75 \%$ water $/ 15 \%$ methanol/10\% acetic acid.

\subsubsection{Characterization of hair keratin extracted: free thiol and disulfide bond quantification}

The concentration of free thiol groups and disulfide bonds in the keratin extracted from human hair was determined following a procedure adapted by Fernandes et al. [14], based on Ellman [22]. Succinctly, $1 \mathrm{~mL}$ of keratin solution was added to $5 \mathrm{~mL}$ of $0.5 \mathrm{M}$ phosphate buffer, $\mathrm{pH} 8.0$, containing $100 \mu \mathrm{L}$ of $4 \mathrm{mg} / \mathrm{mL}$ Ellman's reagent (5,5'-dithiobis(2-nitrobenzoic acid)) solution and incubated for $1 \mathrm{~h}$ at room temperature in the dark. Absorbance was measured at a wavelength of $412 \mathrm{~nm}$. The free thiol content was determined from a calibration curve of L-cysteine standards.

The total amount of sulfur and, consequently, of disulfide bond was determined using a similar reaction with Ellman's reagent after complete reduction of the keratin using sodium borohydride [23]. Briefly, a volume of $1 \mathrm{~mL}$ of extracted keratin was added to $150 \mu \mathrm{L}$ of $0.05 \mathrm{M}$ Tris buffer, $\mathrm{pH} 6.8$ and $1 \mathrm{~mL}$ of freshly prepared $4 \% \mathrm{w} / \mathrm{v}$ sodium borohydride in $0.2 \mathrm{M}$ sodium hydroxide solution. These reagents were incubated for $1 \mathrm{~h}$ in a shaking water bath at $37^{\circ} \mathrm{C}$. Residual sodium borohydride was, then, inactivated with $200 \mu \mathrm{L}$ of $5 \mathrm{M}$ hydrochloric acid for $10 \mathrm{~min}$, under agitation. The $\mathrm{pH}$ of the resulting reaction mixture was adjusted to 8.0 with $2 \mathrm{~mL}$ of $1 \mathrm{M}$ phosphate buffer, $\mathrm{pH}$ 8.0. A volume of $100 \mu \mathrm{L}$ of $4 \mathrm{mg} / \mathrm{mL}$ Ellman's reagent was added and incubated for $15 \mathrm{~min}$ at room temperature. Absorbance at $412 \mathrm{~nm}$ was measured. The number of disulfide bonds present in the keratin was indirectly determined by subtracting the amount of free thiol groups present before sodium borohydride reduction from the amount of free thiols present after this reduction. The experiment was performed in triplicate.

\subsubsection{Labeling of hair keratin extracted with Alexa Fluor 647 carboxylic acid, succinimidyl ester}

The hair keratin, $4.5 \mathrm{mg} / \mathrm{mL}$ in $0.1 \mathrm{M}$ sodium bicarbonate $\mathrm{pH}$ 8.3, was labeled with Alexa Fluor 647 carboxylic acid, succinimidyl ester in $5 \%$ anhydrous dimethyl sulfoxide (DMSO), in a ratio $5: 1$ [24]. The reaction was incubated for $90 \mathrm{~min}$ in the dark at room temperature. Non-linked Alexa Fluor 647 carboxylic acid, succinimidyl ester was separated by centrifugation using AMICON ultra centrifugal filter with $3 \mathrm{kDa}$ porosity for $1 \mathrm{~h}$ at $5000 \times \mathrm{g}$ at room temperature. The degree of labeling (DOL), the number of moles of dye coupled per mole of protein, was determined by 
$\mathrm{DOL}=\left(\mathrm{A}_{\max } \varepsilon_{280}\right) /\left(\left(\mathrm{A}_{280}-\mathrm{A}_{\max } \times \mathrm{CF}_{280}\right) \varepsilon_{\max }\right)$, where $\mathrm{A}_{\max }$ is the absorption of the dye at maximum absorption wavelength, $A_{280}$ is the absorption of the protein at wavelength $280 \mathrm{~nm}, \varepsilon_{\max }$ is the molar extinction coefficient of the dye at the maximum absorption wavelength $(650 \mathrm{~nm}), \varepsilon_{280}$ is the molar extinction coefficient of the keratin at wavelength $280 \mathrm{~nm}$, calculated through Beer-Lambert law $A_{280}=\varepsilon_{280} l_{\text {cuvette }} C_{\text {protein }}$, where $l_{\text {cuvette }}$ is the cuvette pathlength and $\mathrm{C}_{\text {protein }}$ is the keratin concentration, and $\mathrm{CF}_{280}$ is the correction factor used in the determination of degree of labeling, calculated through $\mathrm{CF}_{280}=\mathrm{A}_{280 \text { ofdye }} / \mathrm{A}_{\text {maxofdye }}$ and determined to be 0.03 .

\subsubsection{Peptides' affinity to keratin}

Each peptide microarray slides included three replicas of 1235 peptides, based on the proteins resulting from the translation of the genes of keratin associated-proteins KRTAP1 to KRTAP13, KRTAP15 to KRTAP17, KRTAP 19 to KRTAP 27, KRTAP 29, keratin type I genes KRT31 to KRT 40 and keratin type II genes KRT 81 to KRT 86. The peptides, with a concentration of $15 \mathrm{fmol} / \mathrm{mm}^{2}$, were attached to glass through a hydrophilic linked moiety. The microarrays also included 49 spots with printed buffer as control. Briefly, the microarray slides, provided from JPT, had the peptides synthesized by spottechnique, where a reactivity tag was attached to the N-terminus of each peptide enabling chemoselective immobilization and peptide purification. This procedure was followed by reformatting the peptide library and printing of the peptide microarray.

According to the slide's manufacturer JPT protocols, the keratin labeled was diluted to $5 \mu \mathrm{g} / \mathrm{mL}$ in blocking buffer containing $3 \%$ w/v BSA and PBST (Phosphate-buffered saline, pH 7.4 with $0.05 \%$ Tween 20). The slides were incubated with the labeled solution of extracted keratins in an incubation chamber for $2 \mathrm{~h}$ at $37^{\circ} \mathrm{C}$. Posteriorly, the slides were rinsed successively in PBST and blocking buffer, for $3 \mathrm{~min}$ in each solution, to remove unbound keratin and salt residues. The slides were dried by blowing with a gentle stream of nitrogen on the microarray surface.

\subsubsection{Microarray imaging and analysis}

Fluorescence scans of the slides were performed using the scan Agilent G2565CA Microarray scanner system, with a red emission filter $(650 \mathrm{~nm}-750 \mathrm{~nm})$ after monochrome excitation at $633 \mathrm{~nm}$. The image was generated with a scan resolution of $5 \mu \mathrm{m}$. The features of the microarray slides were extracted and normalized using an adaptation of MicroArray Image Processing Case Study code from The MathWorks, Inc. and Bioinformatics Toolbox from The MathWorks, Inc., MATLAB. Summarily, an estimation of the spots spacing and detection of the spots was obtained by autocorrelation, as in practice, microarrays spots have different intensities and sizes. From this estimation, the background noise was reduced at a safety margin to the spot region. The spots were detected by image segmentation and its intensity was considered the median of the central area of the spot. Standardization was accomplished by scaling the intensities from zero to one.

\subsubsection{Statistical analysis}

A total of ten variables were studied (Table 1) [25], that were based on the physicochemical properties of the peptides in the microarray and selected by considering the most relevant interactions for the stabilization of keratin networks. We performed an analysis of the variables, checking for the normality of the distributions of the variables through Shapiro-Wilk test. Subsequently, Spearman's correlation was used to determine possible two-way associations between two variables.

To further analyze the peptides properties and to compare the peptides with highest and lowest affinity to keratin, the linkage of keratin to the peptides in the microarray was split into five ranks of intensity (Table 2). These ranks were created by grouping sim-
Table 1

Description of the peptide variables studied.

\begin{tabular}{ll}
\hline Name of the variable & Peptide Property Description \\
\hline $\begin{array}{l}\text { Cysteine } \\
\text { Hydrophobic }\end{array}$ & $\begin{array}{l}\text { Content of cysteine residues } \\
\text { Content of hydrophobic amino acids (phenylalanine, } \\
\text { alanine, methionine, leucine, isoleucine, tryptophan, } \\
\text { proline, valine) } \\
\text { Content of amino acids with polar side chains } \\
\text { (glutamine, glycine, asparagine, serine, tyrosine, } \\
\text { threonine) } \\
\text { Content of amino acids with basic side chains at pH 7 } \\
\text { (histidine, arginine, lysine) } \\
\text { Basic }\end{array}$ \\
Acidic & $\begin{array}{l}\text { (aspartic acid, glutamic acid) } \\
\text { Content of amino acids with aromatic ring } \\
\text { Aroma }\end{array}$ \\
Amide & $\begin{array}{l}\text { Content of amino acids with amide side chains } \\
\text { (asparagine, glutamine) }\end{array}$ \\
Alcohol & $\begin{array}{l}\text { Content of amino acids with alcohol side chains } \\
\text { (serine, tyrosine) }\end{array}$ \\
pI & $\begin{array}{l}\text { Isoelectric point } \\
\text { Net charge of the peptide at pH 7 }\end{array}$ \\
Net &
\end{tabular}

Table 2

Division of the peptides into five ranks, according to the average intensity of the keratin in that microarray spot.

\begin{tabular}{ll}
\hline Rank of Intensity & Intensity \\
\hline 0 & 0.00 \\
1 & Between 0.00 and 0.25 \\
2 & Between 0.25 and 0.50 \\
3 & Between 0.50 and 0.75 \\
4 & Between 0.75 and 1.00 \\
\hline
\end{tabular}

Table 3

Division of the peptides into two ranks, according to the average intensity of the keratin in that microarray spot.

\begin{tabular}{ll}
\hline Rank of Intensity & Intensity \\
\hline$A$ & Between 0.00 and 0.75 \\
$B$ & Between 0.75 and 1.00 \\
\hline
\end{tabular}

ilar intensities of keratin in the spots of peptides that could best describe their different distributions along all the range of possible intensities. A non-parametric Kruskal-Wallis test was performed for each of the peptide variables using these five ranks of intensity as dependent variable (Table 2) to determine if there were significant differences between them. Bonferroni correction was applied to correct for multiple testing. Posteriorly, the overall span of the keratin linked to the peptides was divided into just two ranks (Table 3) to better understand the characteristic differences of the very high affinity peptides. Mann-Whitney was performed to the same variables but regarding these two ranks of intensities. For all the statistical analysis, $p$-values $\leq 0.05$ were considered statistically significant. All the statistical analysis and results were produced in IBM $^{\circledR}$ SPSS $^{\circledR}$ Statistics, version 22.

\section{Results and discussion}

\subsection{General characteristics of the keratin extracted from human hair}

Aiming to test the characteristics of peptides that lead to a higher affinity and interaction to the human hair keratins, we first extracted and analyzed the keratin from human hair fibers.

Keratin was extracted by sulfitolysis, where the disulfide bonds of the cystines are cleaved by the sulfite $[19,20]$. The yield of the extraction was approximately $30 \%$, as expected from similar extractions [19]. This method of extraction does not provide a high yield 


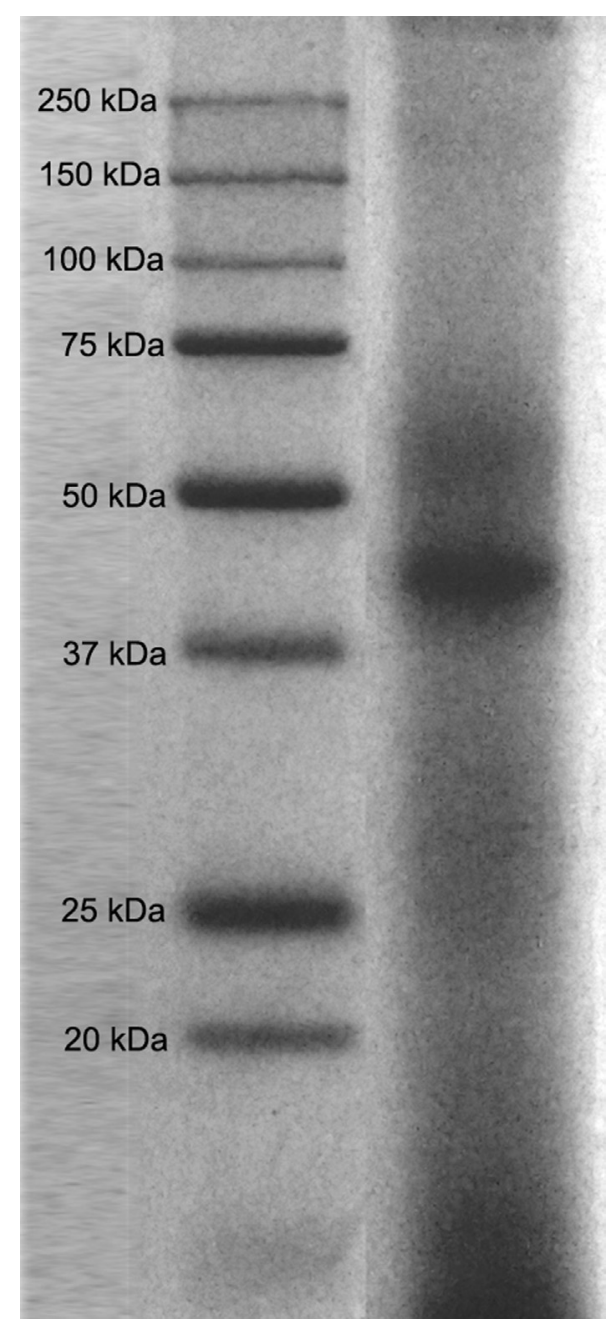

Fig. 1. SDS-PAGE electrophoresis of keratin extracted.

but allows a better keratin solubility. The keratin extracted contained two types of keratins (Fig. 1). The most prominent band is at $\sim 40 \mathrm{kDa}$. This band is inside the expected range of molecular weight for the human alpha-keratins ( $\sim 40$ to $\sim 68 \mathrm{kDa}$ ), mainly type I acidic keratins [26]. The other band is in the range of around $60 \mathrm{kDa}$, characteristic of type II keratins. As this band is slightly less visible, it suggests an inferior content of this type of keratin when compared with type I. Along the paper we will designate this extracted protein mixture as keratin solution. We further characterized the keratin solution regarding the content of sulfur and its redox state.

Sulfur analysis reflects the cysteine redox status of the keratin extracted. The majority of the sulfur (96\%) was in the form of disulfide bonds $(2.944 \pm 0.497 \mu \mathrm{M})$. Free thiol was only $4 \%$ of the sulfur of the extracted keratin $(0.103 \pm 0.002 \mu \mathrm{M})$. This ratio between disulfide bonds and free thiol are similar to the cystine and cysteine found in Clay et al. [27] and Ward et al. studies [28]. This suggests the keratin extracted is in a redox status similar to the native one of an unaltered human hair, allowing the study of the interactions between the peptides and the keratin of the human hair in a similar context as the unaltered human hair.

\subsection{Peptide microarray design}

A high-density peptide dot matrix was used for simultaneous and parallel screening of the chemical interactions of a vast number of peptides with the hair keratin within a single experiment [29]. A representative image of one of the peptide microarrays is pictured in Fig. 2 . These interactions occur between two different types of species, one immobilized on a solid support, in our case, 10-11-mer peptides whose sequences were derived from human hair keratins and KAPs, and another solubilized in a liquid sample, in our case, a solution of keratins extracted from hair [30].

The design of the array peptides was based on the amino acid sequence of human hair keratins and KAPs, whose domains are known to participate in intra- and intermolecular interactions. The major bond present in these interactions is the disulfide bond, playing an important role in the stabilization of the keratin network and structure $[4,6]$. For this reason, all the selected array peptides were cysteine-containing peptides. The small size of the peptides, apart from being advisable concerning synthesis purity, serves another future aim which is to enable an easier diffusion into the hair cortex, in case the peptides are to be applied to hair.

All the selected 10-11mer peptide sequences (1235 different sequences) contained $20 \%-45 \%$ cysteine content. Most peptides had hydrophobic amino acids (78\%) and amino acids with polar side chains (70\%); the number of these amino acids varied from one to eight. Approximately half of the peptides did not have in their sequence basic amino acids (50\%) neither amino acids with an amide side chain (53\%); the other half of peptides contained one to four of these amino acids. Most peptides had no amino acid with acidic (81\%) nor with aromatic side chains (92\%); a few percentage contained one, two or in a residual percentage three of these amino acids in their sequence. Most peptides contained amino acids with an alcohol side chain (83\%), which contained from one to six of these amino acids.

The peptides have isoelectric point (pI) from acidic to basic, divided into four major groups: two acidic, pI from 3.67 to 4.00 and pI from 5.48 to 5.55 , one slightly acid with pI from 6.70 to 6.72 and one slightly basic with pI from 7.79 to 8.43 . The net charge varied from -0.3 to 0.3 .

The detection of the affinity of the peptides to the keratin fraction was achieved with a fluorescence labeled probe, Alexa Fluor 647 succinimidyl ester conjugated with the extracted hair keratins [30]. This fluorescent dye was chosen due to its photostability and intense fluorescence [24,31]. In this conjugation, we a degree of labeling of $0.9 \mathrm{~mol}$ of Alexa Fluor 647 per mole of keratin. This value is not higher due to the primary amine present in the keratin composition, which reduces the labeling of the dye to the keratin.

The negative control spots of the microarray with printed buffer had a normalized intensity of $0.085 \pm 0.049$ out of 1 in the scale of intensity. This intensity is most likely due to hydrogen bonds between the keratin extracted to the printed buffer indicating that even though the microarray slides were washed, these type of interactions remained.

Brief data quality diagnostics were performed: variability was reasonably moderate between the different arrays, and there is no significant visual evidence of spatial patterns over the microarray slide surfaces due to a putative incorrect distribution of the keratinlabeled along the slide. As so, for the analysis of the microarray, we assume that a higher intensity in each spot in the microarray corresponds to a higher affinity of that peptide to the hair keratin, as it indicates a higher concentration of the hair keratin fraction linked to that specific spot.

\subsection{Correlation of peptides characteristics}

The selected peptide variables are not expected to be independent amongst themselves since some of them derive from the existence of similar structures and composition. As so, a first analysis aimed to study how the different characteristics correlated between them, in order to have a better understanding of them.

None of the other variables were normally distributed, not even the distribution within each rank, according to Shapiro-Wilk test 


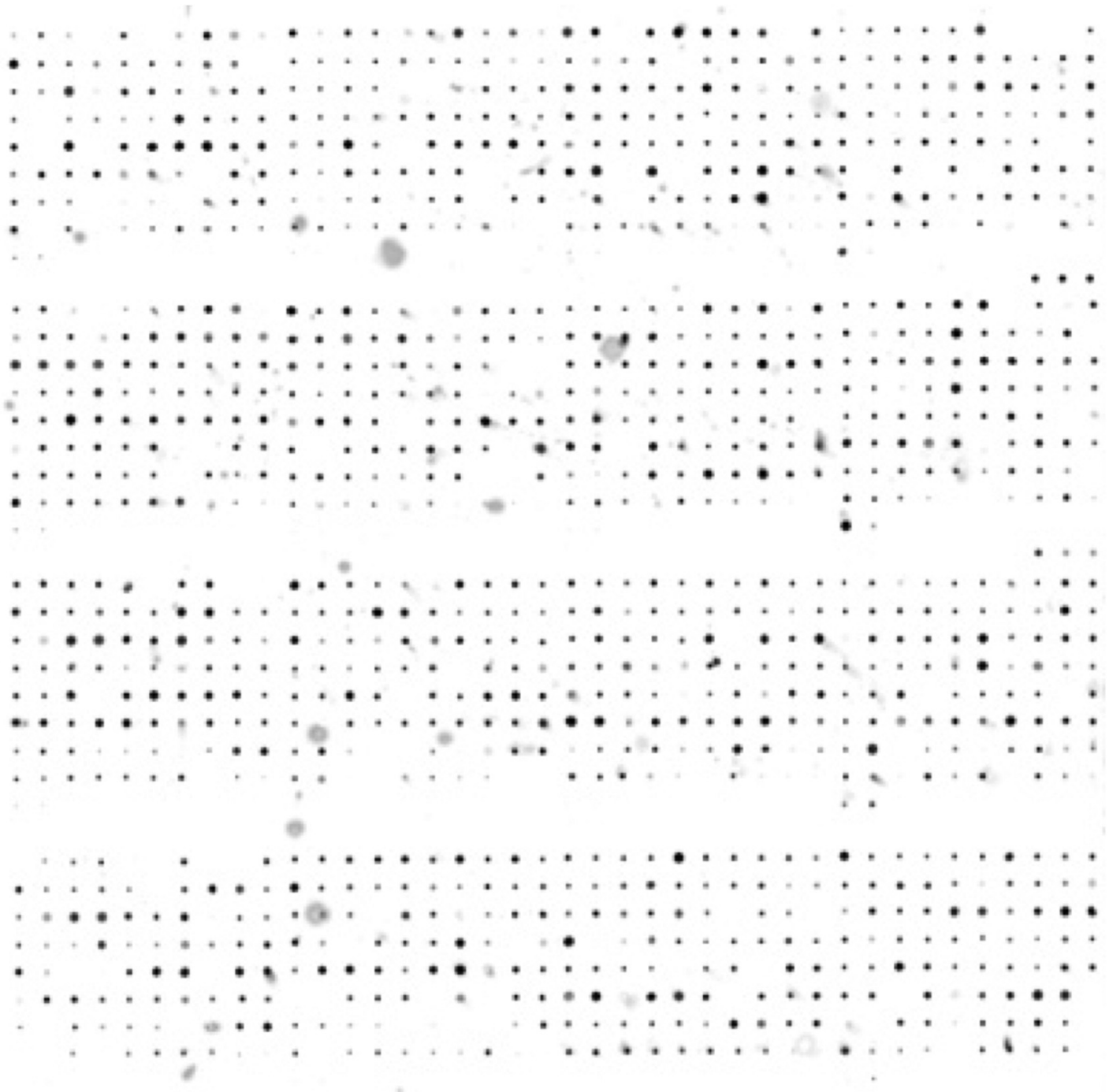

Fig. 2. Representative image of one of the peptide microarrays.

(data not shown, all variables with a p-value $\leq 0.05$ ). Therefore, all the subsequent statistical analyses were performed with nonparametric tests.

The first approach was the use of Spearman's correlation test as a filter to assess the strength of the putative correlation between the different variables [32]. This test was chosen as it is less sensitive to data outliers. Considering very high correlated variables when correlation coefficients above 0.75 , in absolute value, the content of amino acids with basic side chains, isoelectric point and net charge were found to be highly correlated variables (Table 4 ). This was expected as the basic side chains are ionizable, affecting the peptide net surface charge, which is reflected in both net charge at $\mathrm{pH} 7$ and isoelectric point (the $\mathrm{pH}$ at which the charge is neutral). However, it is interesting to note that the isoelectric point and net charge were not found to be very highly correlated with the content of amino acids with acidic side chains, although their side chains are also ionizable. This can be explained by the fact that the selected peptides had a very low content of amino acids with acidic side chains (only $19 \%$ of designed peptides had acidic amino acids in their sequence). However, amino acids with acidic side chains and net charge are also considered high correlated, as their correlation is, in absolute value, below 0.75 and above 0.50 . The amino acids with polar and alcohol side chains are also high related. This is expected as amino acids with alcohol side chains (serine and tyrosine) are also considered amino acids with polar side chains. The content of amino acids with polar side chains and hydrophobic amino acid are high inversely correlated. This result is expected as, for molecular stability purposes, amino acids with similar behavior in aqueous media should be in a nearby location in the keratin and keratin associated proteins. As these peptides are based on these proteins, it is expected that their relation is similar.

It should also be noted that there are no perfectly correlated variables (with correlation coefficients above 0.950 , in absolute value). Variables with low correlation (below 0.25 , in absolute value) coefficient are considered independent variables.

\subsection{Multivariable analysis of peptide characteristics with keratin affinity}

The degree of keratin affinity to the peptides in the microarray was divided into five ranks based on normalized fluorescence intensity to determine the peptides with highest and lowest affinities to keratin, statistically significant (Table 2).

A non-parametric Kruskal-Wallis test was performed for the different variables (Table 1 ) with the spot intensity as the dependent variable, in order to determine if there were significant differences between the ranks (Table 5 and Fig. 3). Dunn-Bonferroni correction was implemented for multiple testing between the variables. 
Table 4

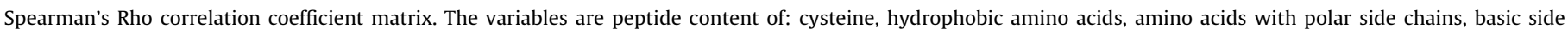

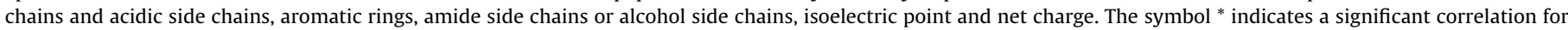
$\mathrm{p}$-value $\leq 0.05$ level and ${ }^{* *}$ for $\mathrm{p}$-value $\leq 0.01$. If there is no indication, it is not 2 -tailed significant.

\begin{tabular}{|c|c|c|c|c|c|c|c|c|c|c|}
\hline & Cysteine & Hydrophobic & Polar & Basic & Acidic & Aroma & Amide & Alcohol & $\mathrm{pI}$ & Net \\
\hline Cysteine & & $-0.302^{* *}$ & $-0.327^{* *}$ & -0.041 & $-0.208^{* *}$ & $-0.149^{* *}$ & -0.025 & $-0.0209^{* *}$ & 0.058* & $-0.096^{* *}$ \\
\hline Hydrophobic & & & $-0.642^{* *}$ & -0.021 & -0.007 & $0.229^{* *}$ & $-0.115^{* *}$ & $-0.325^{* *}$ & 0.000 & 0.020 \\
\hline Polar & & & & $-0.310^{* *}$ & $-0.073^{*}$ & $-0.105^{* *}$ & $0.282^{* *}$ & $0.584^{* *}$ & $-0.252^{* *}$ & $0.203^{* *}$ \\
\hline Basic & & & & & $-0.116^{* *}$ & 0.038 & $-0.213^{* *}$ & $-0.190^{* *}$ & $0.844^{* *}$ & $-0.776^{* *}$ \\
\hline Acidic & & & & & & -0.013 & -0.016 & -0.009 & $-0.487^{* *}$ & $0.577^{* *}$ \\
\hline Aroma & & & & & & & $-0.056^{*}$ & -0.045 & 0.052 & -0.038 \\
\hline Amide & & & & & & & & $0.082^{* *}$ & $-0.173^{* *}$ & $0.170^{* *}$ \\
\hline Alcohol & & & & & & & & & $-0.181^{* *}$ & $0.148^{* *}$ \\
\hline pI & & & & & & & & & & $-0.934^{* *}$ \\
\hline Net & & & & & & & & & & \\
\hline
\end{tabular}

Table 5

Non-parametric Kruskal-Wallis test and Dunn-Bonferroni correction for multiple testing. The tests were performed considering the division of intensities into five ranks.

\begin{tabular}{|c|c|c|c|c|c|c|c|c|c|}
\hline \multirow[t]{3}{*}{ Variables } & \multicolumn{4}{|c|}{ Kruskal- Wallis test } & \multirow{2}{*}{\multicolumn{5}{|c|}{$\frac{\text { Dun-Bonferroni correction }}{\text { Adjusted significance between rank }}$}} \\
\hline & \multirow[t]{2}{*}{ Chi-square } & \multirow[t]{2}{*}{ Asymp sig } & \multirow[t]{2}{*}{ Rank of intensity } & \multirow{2}{*}{$\begin{array}{l}\text { Mean statistical } \\
\text { rank }\end{array}$} & & & & & \\
\hline & & & & & 0 & 1 & 2 & 3 & 4 \\
\hline \multirow[t]{5}{*}{ Cysteine } & 38.4 & 0.00 & 0 & 677.6 & & 0.00 & 0.33 & 1.00 & 1.00 \\
\hline & & & 1 & 565.3 & & & 0.70 & 0.00 & 0.09 \\
\hline & & & 2 & 610.8 & & & & 0.01 & 0.21 \\
\hline & & & 3 & 733.4 & & & & & 1.00 \\
\hline & & & 4 & 729.8 & & & & & \\
\hline \multirow[t]{5}{*}{ Hydrophobicity } & 11.0 & 0.03 & 0 & 651.5 & & & & & \\
\hline & & & 1 & 608.1 & & & 1.00 & 1.00 & 0.02 \\
\hline & & & 2 & 580.7 & & & & 0.86 & 0.07 \\
\hline & & & 3 & 647.7 & & & & & 1.00 \\
\hline & & & 4 & 722.6 & & & & & \\
\hline \multirow[t]{5}{*}{ Polar } & 50.5 & 0.00 & 0 & 572.0 & & 0.00 & 0.62 & 0.29 & 0.08 \\
\hline & & & 1 & 673.6 & & & 1.00 & 0.00 & 0.00 \\
\hline & & & 2 & 631.9 & & & & 0.00 & 0.00 \\
\hline & & & 3 & 483.0 & & & & & \\
\hline & & & 4 & 426.8 & & & & & \\
\hline \multirow{5}{*}{ Basic } & 77.5 & 0.00 & 0 & 472.7 & & 0.00 & 0.00 & 0.00 & 0.02 \\
\hline & & & 1 & 603.6 & & & 0.00 & 0.02 & 1.00 \\
\hline & & & 2 & 718.7 & & & & 1.00 & 0.65 \\
\hline & & & 3 & 707.6 & & & & & \\
\hline & & & 4 & 627.5 & & & & & \\
\hline \multirow[t]{5}{*}{ Acidic } & 70.3 & 0.00 & 0 & 736.5 & & 0.00 & 0.00 & 0.00 & 0.01 \\
\hline & & & 1 & 609.6 & & & 0.04 & 1.00 & 1.00 \\
\hline & & & 2 & 558.4 & & & & 1.00 & 1.00 \\
\hline & & & 3 & 589.3 & & & & & 1.00 \\
\hline & & & 4 & 610.2 & & & & & \\
\hline \multirow[t]{5}{*}{ Aroma } & 1.3 & 0.86 & 0 & 627.2 & & & & & \\
\hline & & & 1 & 613.2 & & & & & \\
\hline & & & 2 & 624.7 & & & & & \\
\hline & & & 3 & 603.2 & & & & & \\
\hline & & & 4 & 629.5 & & & & & \\
\hline \multirow[t]{5}{*}{ Amide } & 2.3 & 0.68 & 0 & 632.9 & & & & & \\
\hline & & & 1 & 622.5 & & & & & \\
\hline & & & 2 & 608.5 & & & & & \\
\hline & & & 3 & 617.7 & & & & & \\
\hline & & & 4 & 560.8 & & & & & \\
\hline \multirow[t]{5}{*}{ Alcohol } & 16.5 & 0.00 & 0 & 618.5 & & 1.00 & 1.00 & 0.59 & 0.11 \\
\hline & & & 1 & 643.4 & & & 1.00 & 0.05 & 0.01 \\
\hline & & & 2 & 623.3 & & & & 0.36 & 0.07 \\
\hline & & & 3 & 542.0 & & & & & \\
\hline & & & 4 & 481.0 & & & & & \\
\hline \multirow[t]{5}{*}{$\mathrm{pI}$} & 139.8 & 0.00 & 0 & 403.2 & & 0.00 & 0.00 & 0.00 & 0.00 \\
\hline & & & 1 & 600.6 & & & 0.00 & 0.01 & 1.00 \\
\hline & & & 2 & 766.8 & & & & 1.00 & 0.23 \\
\hline & & & 3 & 725.1 & & & & & 0.00 \\
\hline & & & 4 & 645.9 & & & & & \\
\hline \multirow[t]{5}{*}{ Net } & 148.5 & 0.00 & 0 & 826.0 & & 0.00 & 0.00 & 0.00 & 0.00 \\
\hline & & & 1 & 636.7 & & & 0.00 & 0.00 & 1.00 \\
\hline & & & 2 & 474.4 & & & & 1.00 & 0.69 \\
\hline & & & 3 & 515.7 & & & & & 0.00 \\
\hline & & & 4 & 565.5 & & & & & \\
\hline
\end{tabular}



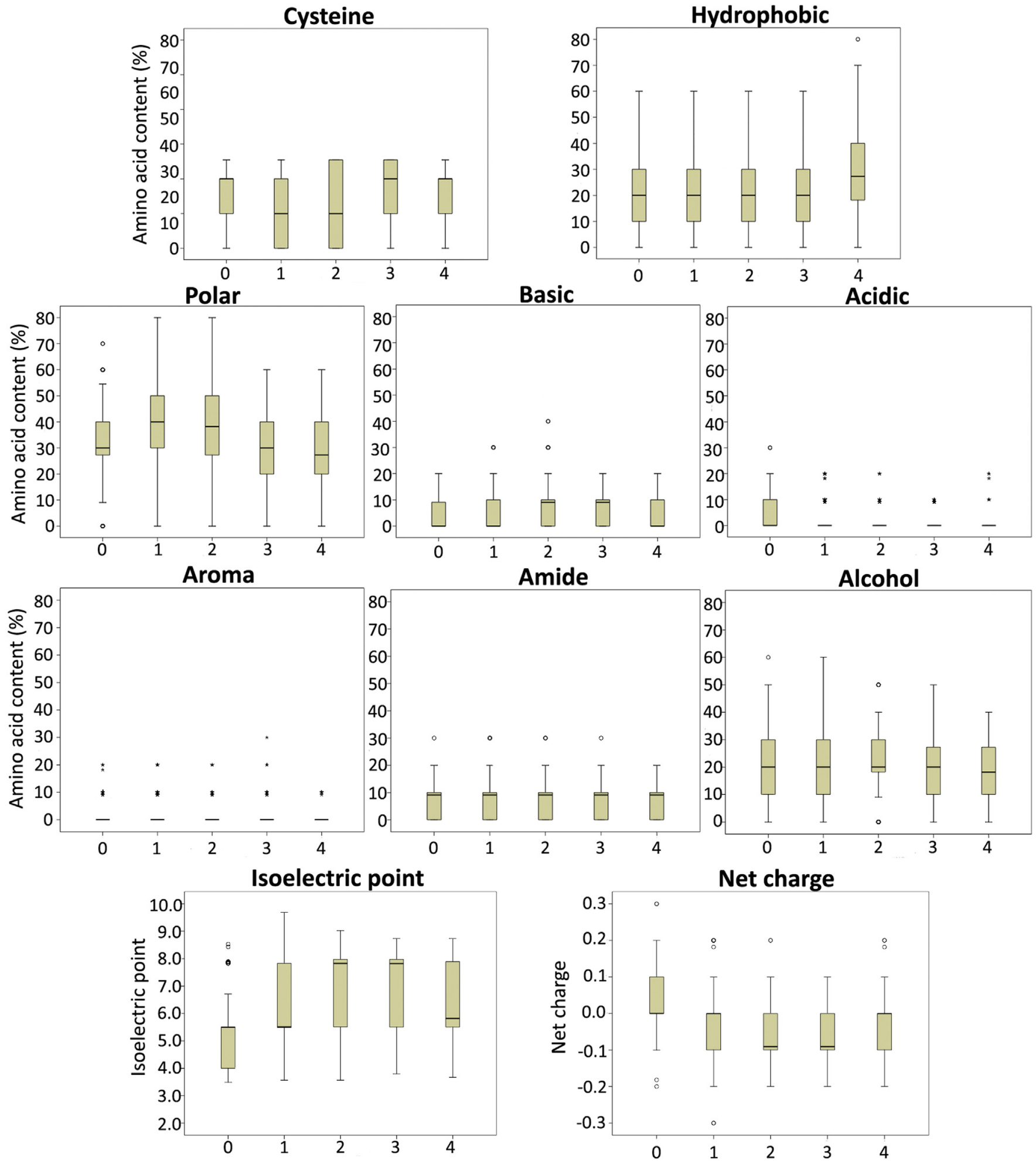

Hydrophobic
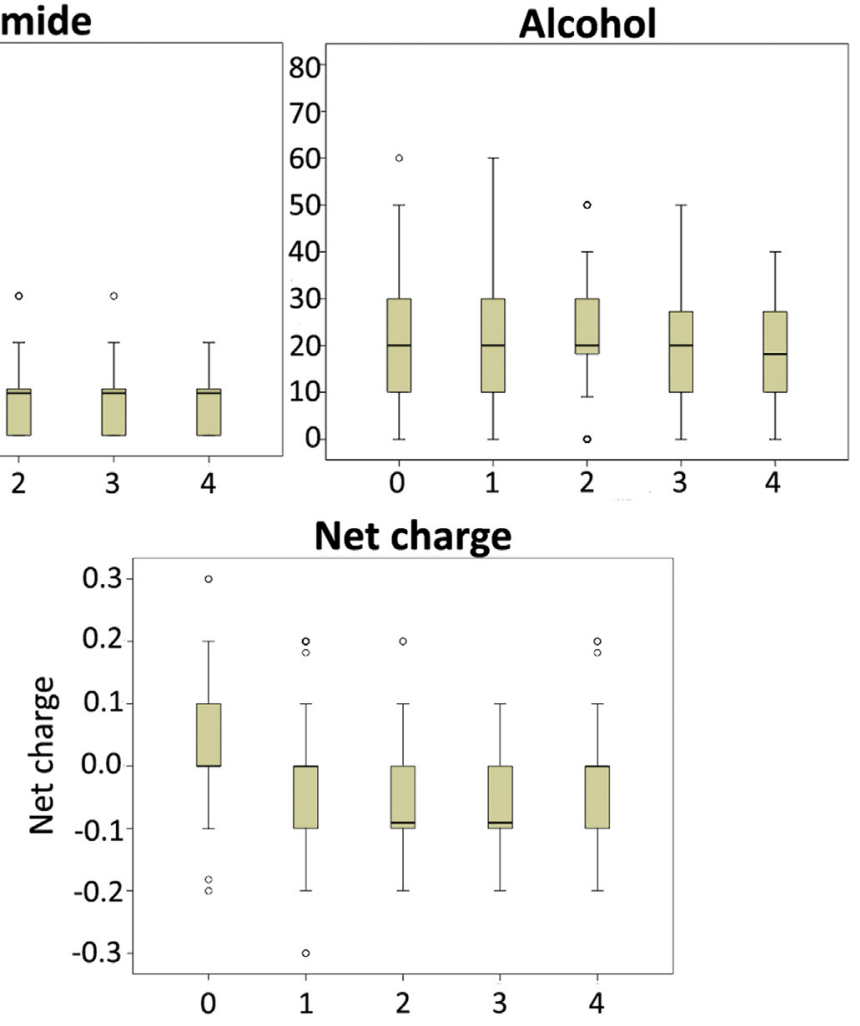

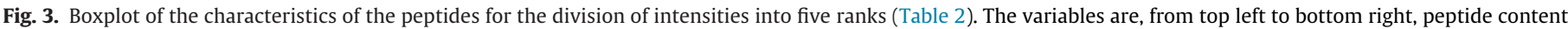

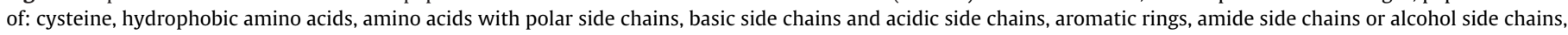
isoelectric point and net charge.

For all variables, except amide and aromatic side chains, the different ranks of intensity representing ranks of affinity of keratin to the peptides are statistically different ( $p$-value $\leq 0.05$ ) between (Table 5). As amide and aromatic side chains did not show statistically difference between the different ranks of affinity of keratin to the peptides, Dunn-Bonferroni correction could not be performed in these variables (Fig. 3).

Regarding the cysteine content of the peptides, Fig. 4 there was statistically significant differences between the middle and the highest affinity of hair keratin to the peptides (statistically different ranks: rank 0 and rank 1 , rank 1 and rank 3 , rank 1 and rank 4 , rank 
Cysteine

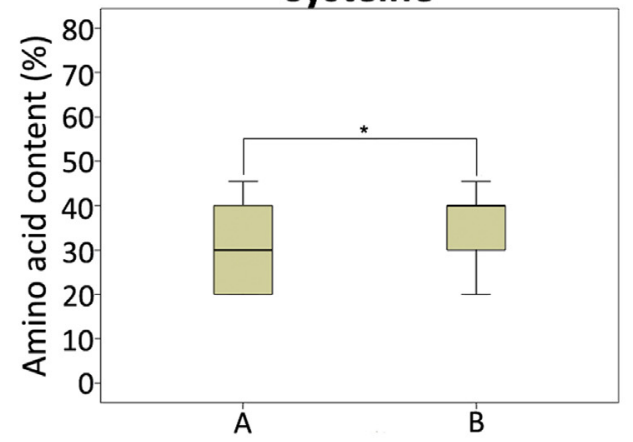

Polar

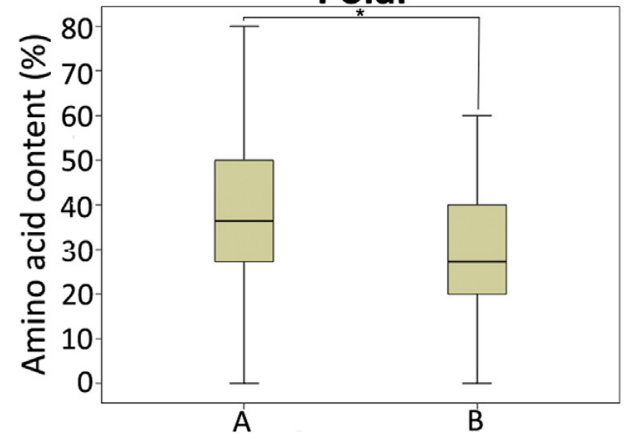

Aroma

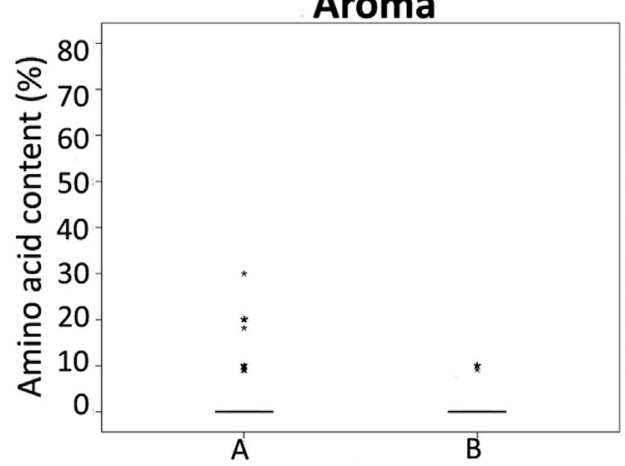

Hydrophobic

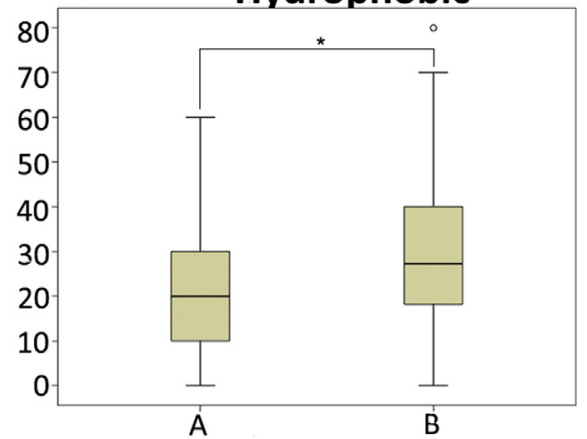

Acidic

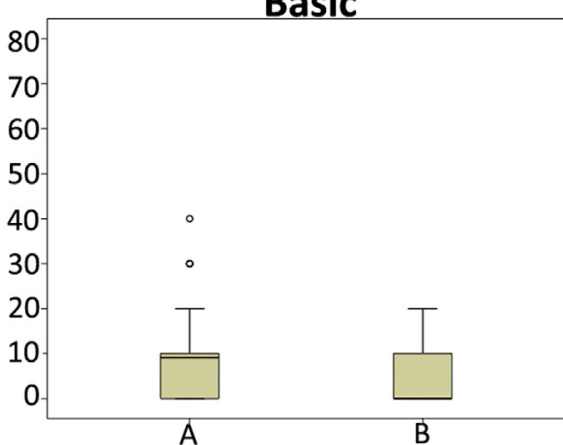

Amide

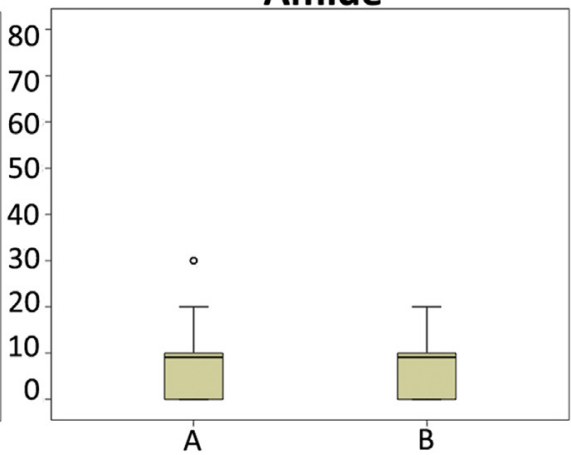

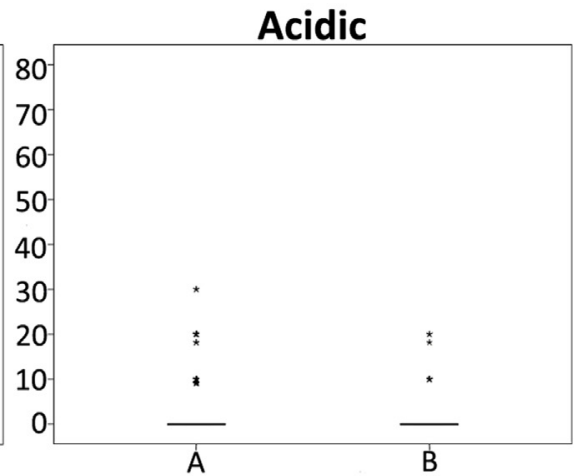

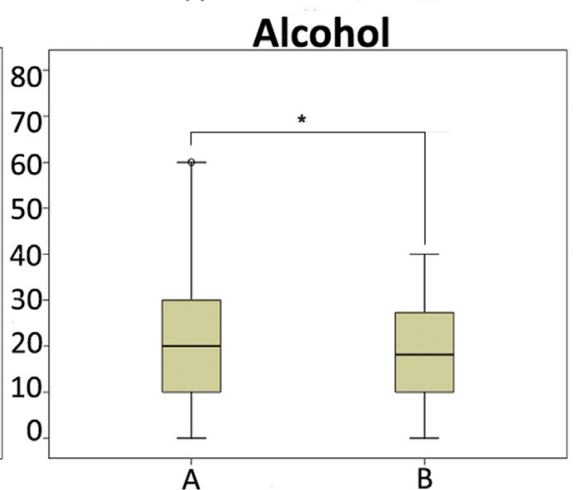

Isoelectric point
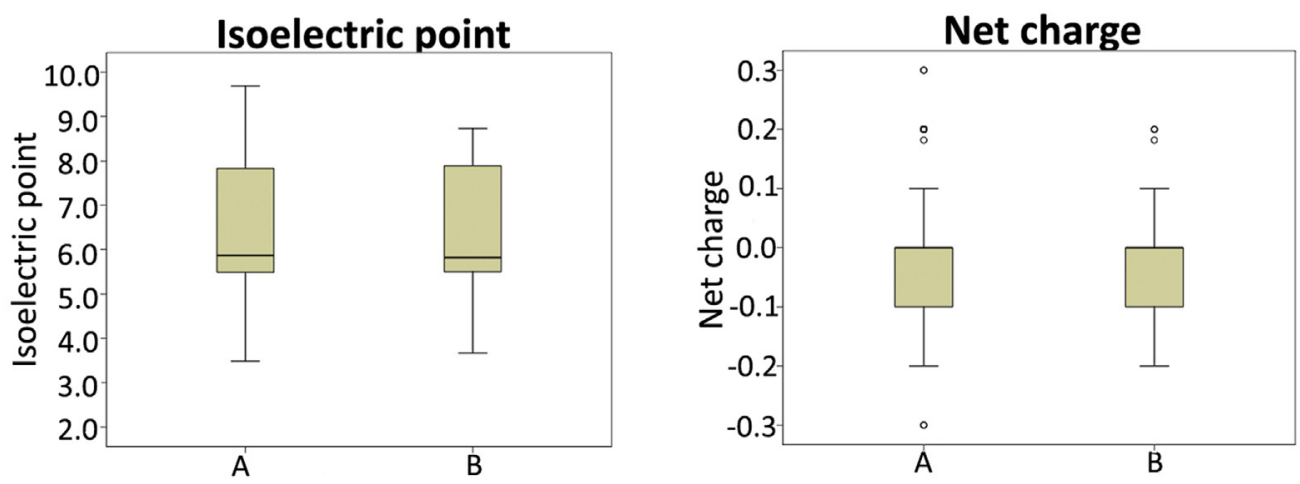

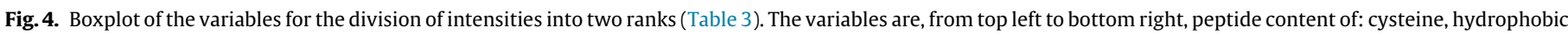

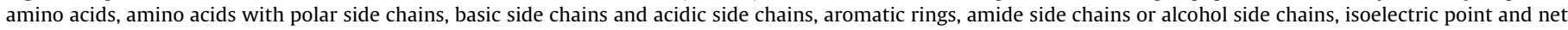
charge. The symbol * indicates a statistical significance for a p-value $\leq 0.05$.

2 and rank 3), but without a clear understanding of the relation between the affinity of hair keratin and the peptides.

Peptides with the highest affinity to keratin had, in general, higher content of hydrophobic amino acids. Hydrophobic interactions are known to be major forces that maintain the coiled-coil structure of keratin in intermediate filaments formation [4,33]; this type of interactions can also favor the affinity of synthetic peptides to hair keratin.

In line with the previous results referred, a slightly inferior content in polar amino acids, such as amino acids containing alcohols, leads to a higher affinity of the peptides to the keratin. The content of polar amino and amino acids containing alcohols was statistically different between the ranks corresponding to middle and highest 
Table 6

Non-parametric Mann-Whitney. The test was performed considering the division of intensities into two ranks.

\begin{tabular}{lll}
\hline Variables & Mann-Whitney $U$ & Asymp sig. \\
\hline Cysteine & 25398.0 & $\mathbf{0 . 0 2}$ \\
Hydrophobicity & 25780.0 & $\mathbf{0 . 0 3}$ \\
Polar & 21190.0 & $\mathbf{0 . 0 0}$ \\
Basic & 30822.0 & 0.83 \\
Acidic & 30908.0 & 0.81 \\
Aroma & 30711.5 & 0.72 \\
Amide & 28288.5 & 0.20 \\
Alcohol & 24061.5 & $\mathbf{0 . 0 0}$ \\
pI & 29843.5 & 0.56 \\
Net & 28539.0 & 0.24 \\
\hline
\end{tabular}

intensity. These results indicate that, although in hair the formation of hydrogen bonds is important for keratin structure, they are not so important in the interaction of keratin with small peptides. For the highest affinities other forces and hence other peptide features must be considered.

The variables content of amino acids with basic side chains, isoelectric point and net charge, previously considered highly correlated, presented statistically significant differences between the lower intensity ranks, but concerning the ranks of higher intensity values, there were no significant differences. Peptides with higher content of basic side chains, higher isoelectric points and more negative net charges have, in general, moderate to higher affinity to keratins extracted from human hair.

The presence of acidic amino acids in the peptide sequence decrease or eliminates the affinity to hair keratin, except for a few outliers corresponding to peptides containing these types of amino acids. In the case of these outliers, other amino acids or their particular position in the peptide sequence can be the determinant factor. As observed in the electrophoresis, the majority of the hair keratins extracted are type I keratins, with an acidic isoelectric point (pI 4.7-5.4) [34,35]. Consequently, peptides with higher isoelectric point and more negative charges and basic will have more affinity to hair keratin. Looking to rank 4 (the peptides in the spots with highest keratin concentration, hence fluorescence intensity) the same tendency does not occur. This may be explained by the fact that for moderate to high affinities, denoted by ranks 3 and 4, one of the major bonding could be ionic. As referred for the variables polar side chains or alcohol-containing side chains (able to participate in hydrogen bonding), to obtain the highest affinities other forces than coulombic forces could be more important. Therefore, in the design of hair care peptides, basic amino acids content, pI and net charge could be reduced to certain level without influencing the affinity to hair keratin.

To assess if the high affinity peptide profile is different from the remaining peptides, a new division of intensities was established: rank $A$ for peptides with intensities between 0.00 and 0.75 ; rank $B$ for peptides with intensities between 0.75 and 1.00 .

According to the Mann-Whitney analysis for the new division criteria the two ranks of intensity were statistically different regarding the content of cysteine, hydrophobic amino acids, polar amino acids and amino acids containing alcohol (Table 6 and Fig. 4). The peptides with higher affinity for the keratin solution had higher cysteine and hydrophobic content, and less polar amino acids and amino acids containing alcohols (Fig. 4). In this analysis, the impact of the presence of cysteine was clearly evident. This result is expected: a higher content of cysteine leads to a higher affinity of the peptide to the keratin, most likely due to the propensity of the formation of disulfide bonds between cysteines among inter- and intra- chains of the keratin [4,33]. A higher affinity to hair keratins in peptides with higher content in amino acids with higher hydrophobic side chains and cysteines and fewer amino acids with polar side chains, including alcohols, suggest that the main driving forces for the observed affinity are the formation of hydrophobic interactions and disulfide bonds between the peptides and extracted keratin.

The main interactions observed between keratins and KAPs correspond to extensive disulfide bond cross-linking with the abundant cysteine residue of KAPs and hair keratins [36-39]. Hydrophobic interactions are also known to stabilize the coiledcoils of $\alpha$-helix keratins [39]. Also, KAPS are thought to be associated by hydrophobic interactions. Consequently, as these peptides are based in hair keratins and KAPs, the small peptides and the keratin extracted from hair should have similar interactions.

The array analysis here reported suggests that the design of small peptides with high affinity to human hair keratin, therefore with good probability to interact and reinforce keratin properties, must be performed considering the main players: hydrophobic interactions and disulfide bonding.

Therefore, these type of peptides could be used for hair cosmetic purposes, mainly for repairing human damaged hair. Damaged hair, due to cosmetic procedures such as bleaching, hair dyeing, and shape-modulating cosmetics, have impaired chemical and mechanical properties $[4,18]$. Peptides with these characteristics could be used for penetration into the hair cortex due to the small size and damaged cuticle, and for enabling reinforcement of the hair fiber structure due to disulfide bonding and hydrophobic interactions $[11,14,16,40]$.

\section{Conclusions}

In this study, a screening on a peptide microarray was used to assess the characteristics of small peptides containing cysteines, based on hair keratin and KAPs, most important to determine their affinity to hair keratin.

Content of cysteine, hydrophobic amino acids and polar amino acids, mainly containing alcohols, variables related to the charge of peptide (content of basic and acidic amino acids, isoelectric point and net charge) showed statistically significant differences between the different pre-established intensity ranks related to peptide affinity to hair extracted keratins, thus corresponding to features that have determining roles in keratin affinity.

When the number of intensity ranks was reduced to two, considering the differences between peptides of very high affinity and the remaining, only content of cysteine, hydrophobic amino acids, and polar amino acids, mainly containing alcohols, were statistically different. This suggests the formation of hydrophobic interactions and disulfide bonds as major players in the interaction of such small peptides and keratin. Further experimental studies will be needed to prove these interactions and to demonstrate if they provide the peptides the essential features to recover keratin damage in hair fibers.

Decapeptides based in human keratins and KAPs are a promising approach to develop formulations that can be used to enhance hair keratin strength. These formulations should contain hair swelling agents as well surfactants to increase the penetration of peptides into hair fiber cortex. Peptides with the characteristics determined by us are strong candidates to reinforce hair fibers.

\section{Funding}

We thank the Portuguese Foundation for Science and Technology (FCT) for providing Célia F. Cruz the grant for PhD studies (scholarship SFRH/BD/100927/2014). This work was also supported by FCT under the scope of the strategic funding of UID/BIO/04469/2013 unit, COMPETE 2020 (POCI-01-0145-FEDER006684) and BioTecNorte operation (NORTE-01-0145-FEDER- 
000004) funded by the European Regional Development Fund under the scope of Norte2020 - Programa Operacional Regional do Norte. This study was also supported by the Portuguese Foundation for Science and Technology (FCT) under the scope of the Project RECI/BBB-EBI/0179/2012 (FCOMP-01-0124-FEDER-027462).

\section{Acknowledgements}

Thanks to Professor Manuel dos Santos and Violeta Ferreira (Biology Department, Aveiro University) for the help and allowing me to use the DNA microarray reader and QuantArray software. Thanks to Ana Sofia Abreu for the help and assistance with the reaction of keratin and Alexa Fluor 647 carboxylic acid, succinimidyl ester.

\section{References}

[1] B. Wang, W. Yang, J. McKittrick, M.A. Meyers, Keratin: structure, mechanical properties, occurrence in biological organisms, and efforts at bioinspiration, Prog. Mater. Sci. 76 (2016) 229-318, http://dx.doi.org/10.1016/j.pmatsci. 2015.06.001.

[2] J.F. Conway, D.A.D. Parry, Intermediate filament structure: 3. Analysis of sequence homologies, Int. J. Biol. Macromol. 10 (1988) 79-98, http://dx.doi. org/10.1016/0141-8130(88)90015-3.

[3] H.H. Bragulla, D.G. Homberger, Structure and functions of keratin proteins in simple, stratified, keratinized and cornified epithelia, J. Anat. 214 (2009) 516-559, http://dx.doi.org/10.1111/j.1469-7580.2009.01066.x.

[4] C.R. Robbins, Chemical and Physical Behavior of Human Hair, 4th ed., Springer, Berlin, Heidelberg, 2002, http://dx.doi.org/10.1007/978-3-642-25611-0.

[5] C. Popescu, H. Höcker, Cytomechanics of hair. Basics of the mechanical stability, Int. Rev. Cell Mol. Biol. 277 (2009) 137-156, http://dx.doi.org/10. 1016/S1937-6448(09)77004-2, Chapter 4.

[6] C. Bouillon, in: P.J. Wilkinson (Ed.), The Science of Hair Care, second edi, Taylor \& Francis, 2005, 2017, http://dx.doi.org/10.1001/jama.1987.03390150111052.

[7] M.A. Rogers, L. Langbein, S. Praetzel-Wunder, H. Winter, J. Schweizer, Human hair keratin-associated proteins (KAPs), Int. Rev. Cytol. 251 (2006) 209-263, http://dx.doi.org/10.1016/S0074-7696(06)51006-X.

[8] C. Tonin, A. Aluigi, A. Varesano, C. Vineis, Keratin-based nanofibres, in: A. Kumar (Ed.), Nanofibers, INTECH, 2010, 2017, p. 438.

[9] M. Feughelman, The physical properties of alpha-keratin fibers, J. Soc. Cosmet. Sci. 33 (1982) 385-406

[10] T. Bornschlögl, L. Bildstein, S. Thibaut, R. Santoprete, F. Fiat, G.S. Luengo, J. Doucet, B.A. Bernard, N. Baghdadli, Keratin network modifications lead to the mechanical stiffening of the hair follicle fiber, Proc. Natl. Acad. Sci. 201520302 (2016), http://dx.doi.org/10.1073/pnas.1520302113.

[11] G. Secchi, Role of protein in cosmetics, Clin. Dermatol. 26 (2008) 321-325, http://dx.doi.org/10.1016/j.clindermatol.2008.04.004.

[12] J. Gray, Hair care and hair care products, Elsevier Sci. Clin. Dermatol. 19 (2001) 227-236

[13] M.M. Fernandes, C.F. Lima, A. Loureiro, A.C. Gomes, A. Cavaco-Paulo, Keratin-based peptide: biological evaluation and strengthening properties on relaxed hair, Int. J. Cosmet. Sci. 34 (2012) 1-9, http://dx.doi.org/10.1111/j. 1468-2494.2012.00727.x.

[14] M.M. Fernandes, A. Cavaco-Paulo, Protein disulphide isomerase-mediated grafting of cysteine-containing peptides onto over-bleached hair, Biocatal. Biotransformation. 30 (2012) 10-19, http://dx.doi.org/10.3109/10242422. 2012.644436 .

[15] A. Ribeiro, T. Matamá, C.F. Cruz, A.C. Gomes, A.M. Cavaco-Paulo, Potential of human $\gamma \mathrm{D}$-crystallin for hair damage repair: insights into the mechanical properties and biocompatibility, Int. J. Cosmet. Sci. 35 (5) (2013) 458-466, http://dx.doi.org/10.1111/ics.12065.

[16] E. Oshimura, H. Abe, R. Oota, Hair and amino acids: the interactions and the effects, J. Cosmet. Sci. 58 (2007) 347-357, http://www.ncbi.nlm.nih.gov/ pubmed/17728935.

[17] L.J. Wolfram, Human hair: a unique physicochemical composite, J. Am. Acad. Dermatol. 48 (2003) 106-114, http://dx.doi.org/10.1067/mjd.2003.276.

[18] J.M. Dyer, F. Bell, H. Koehn, J.a Vernon, C.D. Cornellison, S. Clerens, D.P. Harland, Redox proteomic evaluation of bleaching and alkali damage in human hair, Int. J. Cosmet. Sci. 35 (6) (2013) 555-561, http://dx.doi.org/10. $1111 /$ ics.12076.
[19] A. Vasconcelos, G. Freddi, A. Cavaco-Paulo, Biodegradable materials based on silk fibroin and keratin, Biomacromolecules 9 (2008) 1299-1305, http://dx. doi.org/10.1021/bm7012789.

[20] K. Katoh, M. Shibayama, T. Tanabe, K. Yamauchi, Preparation and physicochemical properties of compression-molded keratin films, Biomaterials 25 (2004) 2265-2272, http://dx.doi.org/10.1016/j.biomaterials. 2003.09.021.

[21] S. Deb-Choudhury, J.E. Plowman, D.P. Harland, Isolation and analysis of keratins and keratin-associated proteins from hair and wool, in: Methods Enzymol, 1st ed., Elsevier Inc., 2016, pp. 279-301, http://dx.doi.org/10.1016/ bs.mie.2015.07.018.

[22] G.L. Ellman, Tissue sulfhydryl groups, Arch. Biochem. Bio- Phys. 82 (1959) 70-77, http://dx.doi.org/10.1016/0003-9861(59)90090-6.

[23] R.E. Hansen, H. Østergaard, P. Nørgaard, J.R. Winther, Quantification of protein thiols and dithiols in the picomolar range using sodium borohydride and 4,4'-dithiodipyridine, Anal. Biochem. 363 (2007) 77-82, http://dx.doi.org/10. 1016/j.ab.2007.01.002.

[24] N. Panchuk-Voloshina, R.P. Haugland, J. Bishop-Stewart, M.K. Bhalgat, P.J. Millard, F. Mao, W.Y. Leung, R.P. Haugland, Alexa dyes, a series of new fluorescent dyes that yield exceptionally bright, photostable conjugates, J. Histochem. Cytochem. 47 (1999) 1179-1188, http://dx.doi.org/10.1177/ 002215549904700910.

[25] E. Jaspard, D. Macherel, G. Hunault, Computational and statistical analyses of amino acid usage and physico-chemical properties of the twelve late embryogenesis abundant protein classes, PLoS One 7 (2012) e36968, http:// dx.doi.org/10.1371/journal.pone.0036968.

[26] R. Moll, M. Divo, L. Langbein, The human keratins: biology and pathology, Histochem. Cell Biol. 129 (2008) 705-733, http://dx.doi.org/10.1007/s00418008-0435-6.

[27] R.C. Clay, K. Cook, J.I. Routh, Studies in the composition of human hair, J. Am. Chem. Soc. 62 (1940) 2709-2710

[28] W.H. Ward, H.P. Lundgren, The Formation, Composition, and properties of the keratins, Adv. Protein Chem. 9 (1954) 243-297, http://dx.doi.org/10.1016/ S0065-3233(08)60208-9.

[29] C. Chen, H. Zhu, Protein microarrays, Biotechniques 40 (2006) 423-429.

[30] M. Cretich, F. Damin, G. Pirri, M. Chiari, Protein and peptide arrays: recent trends and new directions, Biomol. Eng. 23 (2006) 77-88, http://dx.doi.org/ 10.1016/j.bioeng.2006.02.001.

[31] J.N. Miller, Long-wavelength and near-infrared fluorescence. State of the art, future applications, and standards, Stand. Qual. Assur. Fluoresc. Meas. I 5 (2008) 147-162, http://dx.doi.org/10.1007/4243.

[32] C. Nantasenamat, C. Isarankura-Na-Ayudhya, V. Prachayasittikul, Advances in computational methods to predict the biological activity of compounds, Expert Opin. Drug Discov. 5 (2010) 633-654, http://dx.doi.org/10.1517/ 17460441.2010.492827.

[33] M. Feughelman, Natural protein fibers, J. Appl. Polym. Sci. 83 (2002) 489-507, http://dx.doi.org/10.1002/app.2255.

[34] R.C. Marshall, Characterization of the proteins of human hair and nail by electrophoresis, J. Invest. Dermatol. 80 (1983) 519-524, http://dx.doi.org/10. 1111/1523-1747.ep12535117.

[35] N.R. Barthélemy, A. Bednarczyk, C. Schaeffer-Reiss, D. Jullien, A. Van Dorsselaer, N. Cavusoglu, Proteomic tools for the investigation of human hair structural proteins and evidence of weakness sites on hair keratin coil segments, Anal. Biochem. 421 (2012) 43-55, http://dx.doi.org/10.1016/j.ab. 2011.10.011.

[36] Y. Shimoura, M. Ito, Human hair keratin-associated proteins, J. Investig. Dermatol. Symp. Proc. 10 (2005) 230-233, http://dx.doi.org/10.1016/S00747696(06)51006-X.

[37] D.-D. Wu, D.M. Irwin, Y.-P. Zhang, Molecular evolution of the keratin associated protein gene family in mammals, role in the evolution of mammalian hair, BMC Evol. Biol. 8 (2008) 241, http://dx.doi.org/10.1186/ 1471-2148-8-241.

[38] W. Crewther, R. Fraser, The Chemistry of Keratins, Adv. Protein Chem. 20 (1965) 191-346, http://dx.doi.org/10.1016/S0065-3233(08)60390-3.

[39] M.A. Rogers, H. Winter, L. Langbein, A. Wollschlager, S. Praetzel-Wunder, L.F. Jave-Suarez, J. Schweizer, Characterization of human KAP24.1, a cuticular hair keratin-associated protein with unusual amino-acid composition and repeat structure, J. Invest. Dermatol. 127 (2007) 1197-1204, http://dx.doi.org/10. 1038/sj.jid.5700702.

[40] M.F. Gavazzoni Dias, Hair cosmetics: an overview, Int. J. Trichology 7 (2015) 2, http://dx.doi.org/10.4103/0974-7753.153450. 